\title{
Mengelola Batas dalam Konseling: Standar Menerima Hadiah
}

\author{
Aniyatussaidah*, Happy Karlina Marjo \\ Program Studi Magister Bimbingan dan Konseling, Fakultas Ilmu Pendidikan \\ Universitas Negeri Jakarta \\ *Corresponding Author. Email: Aniyatussaidah_1108820008@mhs.unj.ac.id
}

\begin{abstract}
The purpose of this study was to describe the explanation of gifts in counseling based on ethical and cultural considerations. The method in this research is a literature study, namely by collecting reading material from various scientific articles and then comparing theories and research results, which are then analyzed descriptively. Based on the results of a literature study conducted that counselors can receive gifts from counselees by considering aspects of culture, time of giving, and types of gifts given. Based on cultural considerations, especially in Asia, it is seen that receiving gifts from clients is a natural and appropriate thing to do. In contrast to Western culture, in Western cultures receiving gifts will distort boundaries, change relationships, and create conflicts of interest.
\end{abstract}

\begin{abstract}
Abstrak: Tujuan penelitian ini adalah untuk mendeskripsikan penjelasan hadiah dalam konseling berdasarkan pertimbangan etika dan budaya. Metode dalam penelitian ini adalah studi literatur yaitu dengan mengumpulkan bahan bacaan dari berbagai artikel ilmiah lalu membandingkan teori serta hasil penelitian, yang selanjutnya di analisis secara deskriptif. Berdasarkan hasil studi literatur yang dilakukan bahwa konselor dapat menerima hadiah dari konseli dengan mempertimbangkan aspek budaya, waktu pemberian, dan jenis hadiah yang diberikan. Berdasarkan pertimbangan budaya, khususnya di Asia memandang bahwa menerima hadiah dari konseli adalah hal yang wajar dan patut untuk dilakukan, Berbeda dengan budaya Barat, dalam budaya Barat menerima hadiah akan mendistorsi batasan, mengubah hubungan, dan menciptakan konflik kepentingan.
\end{abstract}

\section{Article History}

Received: 20-11-2021

Revised: 10-12-2021

Accepted: 19-12-2021

Published: 07-01-2022

Key Words:

Boundaries in

Counseling, Gifts,

Ethical, Cultural.

\section{Sejarah Artikel}

Diterima: 20-11-2021

Direvisi: $10-12-2021$

Disetujui: 19-12-2021

Diterbitkan: 07-01-2022

\section{Kata Kunci:}

Batasan dalam Konseling, Hadiah, Etika, Budaya.

How to Cite: Aniyatussaidah, A., \& Marjo, H. (2022). Mengelola Batas dalam Konseling: Standar Menerima Hadiah. Jurnal Paedagogy, 9(1), 144-149. doi:https://doi.org/10.33394/jp.v9i1.4545

\section{Pendahuluan}

Isu batasan dalam konseling sebagian besar mengacu pada pengungkapan diri konselor, sentuhan, barter, biaya, lama dan lokasi sesi, kontak di luar kantor dan pertukaran hadiah antara terapis dan konseli (Zur, 2017). Menurut Gutheil dan Gabbard (dalam Zur, 2017), batas adalah "tepi" dari perilaku yang sesuai. Lazarus dan Zur (2017) mendefinisikan penyeberangan batas sebagai setiap penyimpangan dari praktik analitik tradisional dan manajemen risiko, yaitu, bentuk terapi yang ketat, 'hanya di ruang konseling', jauh secara emosional. Gabbard (dalam Corey, Corey, \& Callanan, 2011) mengutip fenomena lereng licin sebagai salah satu argument yang terkuat untuk hati-hati memantau batas-batas dalam konseling.

Argumen ini didasarkan pada premis bahwa tindakan tertentu dapat menyebabkan kemunduran perilaku etis secara progresif. Selanjutnya, jika para professional tidak mematuhi standar tanpa kompromi, perilaku mereka dapat mendorong hubungan yang berbahaya bagi konseli. Oleh karena itu, menghindari lereng yang licin, konselor disarankan untuk memiliki alasan konseling dalam setiap penyeberangan batas dan untuk mempertanyakan perilaku yang 
tidak konsisten dengan pendekatan teoretis. Pemberian hadiah yang tepat, baik oleh konseli atau terapis, termasuk dalam definisi lintas batas (Zur, 2017).

Penting untuk membedakan antara pelanggaran batas dan penyeberangan batas yang membantu (Williams dalam Zur, 2017). pelanggaran batas terjadi ketika seorang terapis melewati batas kesopanan dan integritas dan menyalahgunakan kekuasaannya untuk mengeksploitasi dan/atau merugikan konseli untuk keuntungan terapis sendiri (Zur, 2017). Pelanggaran batas biasanya melibatkan bisnis eksploitatif atau hubungan seksual. Pelanggaran batas selalu tidak etis dan cenderung ilegal. Namun, penyeberangan batas seperti pemberian hadiah yang tepat, sentuhan non-seksual atau pengungkapan diri sering menjadi bagian dari hubungan terapis-konseli yang tepat dan sehat, dengan demikian, dapat meningkatkan efektivitas terapeutik (Zur, 2017).

Berbeda halnya dengan penulis psikodinamik, hadiah selalu dipermasalahkan karena mereka cenderung menjadi ekspresi dari reaksi transferensi beberapa konflik bawah sadar yang belum terselesaikan. Menurut model psikodinamik, pemberian hadiah bisa menjadi manipulasi untuk mengekspresikan cinta erotis, untuk meyakinkan bahwa konselor mereka tidak menolak mereka, dan sebagai fantasi neurotik bahwa mereka dapat mengontrol konselor mereka (Taboas, et al., 2014). Berdasarkan penilaian tersebut, ada beberapa konselor yang memiliki kebijakan untuk tidak pernah menerima hadiah apapun (Talan, dalam Taboas, et al., 2014; Pierce, 2018), supaya tidak terjadi pelanggaran batas. Kebijakan ini disampaikan di awal, sehingga apabila konseli memberikan hadiah, konselor dapat mengingatkan terkait kebijakan yang sudah disampaikan di awal konseling (Allan, 2017).

Supaya tidak terjadi pelanggaran batas, dan tidak adanya kebingungan lagi seputar boleh atau tidaknya menerima hadiah dari konseli. Taboas, et al.,(2014) dan Beaucoup (2021) setiap pemberian hadiah harus dievaluasi dalam konteks pemberiannya. Zur (2017) juga menyarankan demikian bahwa setiap hadiah harus dipahami dan dievaluasi dalam konteks pemberiannya. Selain itu Kode etik ACA juga telah menerapkan standar bahwa konselor memahami tantangan menerima hadiah dari konseli dan menyadari bahwa dalam beberapa budaya, hadiah kecil adalah tanda hormat dan menunjukkan rasa terima kasih. Ketika menentukan apakah akan menerima hadiah dari konseli atau tidak, konselor perlu mempertimbangkan: Implikasi pada hubungan terapeutik, nilai uang dari hadiah, motivasi konseli untuk memberikan hadiah, dan motivasi konselor untuk menginginkan atau menolak hadiah.

Hal tersebut diperjelas oleh Kimber (2020) yaitu keputusan apakah akan memberi atau menerima hadiah ada di tangan individu yang terlibat. Beberapa konselor mungkin tidak menginginkan bagian dari pemberian hadiah, sementara yang lain akan menerima hadiah. Dalam situasi apa pun hadiah tidak diharapkan atau dihargai. Berlisensi apa pun profesional kesehatan mental harus sangat menyadari potensi keterlibatan etis yang terlibat dalam pemberian hadiah, sehingga konselor dapat menentukan apakah pemberian hadiah kepada seseorang dalam terapi dapat berisiko atau mendorong pertumbuhan terapeutik. Dalam beberapa kasus yang kami ketahui, beberapa terapis dan mahasiswa pascasarjana ketakutan ketika konseli mereka, termasuk anak-anak, memberi mereka hadiah kecil, berpikir bahwa mereka melanggar beberapa jenis kode etik (Taboas, et al., 2014).

Kajian ini perlu dibahas karena beberapa konselor/psikolog yang merasakan kebingungan seputar peran hadiah dalam konseling dan bahwa keadaan ini diperburuk oleh kurangnya diskusi profesional tentang topik tersebut. Kajian mengenai standar menerima hadiah dari konseli juga belum banyak dibahas dalam kajian ilmiah di Indonesia, terkhusus dalam layanan konseling. 


\section{Metode Penelitian}

Penelitian ini menggunakan metode kajian pustaka yaitu dengan mengumpulkan bahan bacaan, mencatat, dan mengolah hasil bacaan (Melfianora, 2017). Data-data yang dibutuhkan dalam penelitian dapat diperoleh dari sumber pustaka atau dokumen. Menurut Zed (2014) pada riset pustaka (library research), penelusuran pustaka tidak hanya untuk langkah awal menyiapkan kerangka penelitian (research design) akan tetapi sekaligus memanfaatkan sumber-sumber perpustakaan untuk memperoleh data penelitian. Sumber data yang digunakan berasal dari data sekunder, dimana data sekunder tersebut dikumpulkan melalui karya tulis baik yang sudah maupun belum dipublikasikan (Embun, 2012), buku teks, jurnal ilmiah, periodical, website, dan sumber-sumber lain yang relevan dengan masalah penelitian. Data yang dikumpulkan selanjutnya dianalisis secara deskriptif kualitatif.

\section{Hasil Penelitian dan Pembahasan}

Mempertahankan batas yang jelas dan tegas sangat penting dalam tradisi analitik (Zur, 2017). Batasan-batasan seperti itu sering kali mencakup penghindaran dari segala perlintasan batas termasuk menerima atau memberikan hadiah kepada klien. Dalam hal hadiah, aturan umum analitik tradisional adalah bahwa hadiah konseli harus dianalisis daripada diterima. Praktisi analisis tradisional cenderung melihat terapis yang menerima hadiah sebagai campur tangan dalam analisis transferensi dengan bertindak dan memuaskan impuls bawah sadar (Zur, 2017). Berbeda dengan tradisi analitik, psikologi humanistik dan terapi feminis telah menekankan pentingnya hubungan kongruen antara terapis dan klien, yang sering ditingkatkan dengan memberi dan menerima hadiah (Zur, 2017). Terapi perilaku, kognitif, perilaku kognitif, keluarga dan kelompok cenderung mendukung setiap penyeberangan batas, termasuk pemberian hadiah yang tepat, jika mereka cenderung meningkatkan efektivitas terapi (Zur, 2017).

Oleh karena itu, tidak ada kode etik atau pedoman organisasi besar yang secara khusus melarang pemberian hadiah dalam terapi (Zur, 2017). Baik organisasi profesional utama AS (yaitu, APA, CAMFT, Feminis, NASW, NBCC), maupun kode etik Kanada (yaitu, CPA, CCA) atau Australia (yaitu, APS, AASW, AIWCW, PACFA) tidak menyebutkan topik hadiah. Terdapat organisasi besar yang membahas mengeni penerimaan hadiah, yaitu APA, namun APA tidak menyebutkan menerima hadiah sebagai tidak etis. APA menyebutkan mengenai standar penerimaaan hadiah, dan hal yang perlu dilakukan sebelum menerima hadiah. Ada beberapa hal yang perlu dipertimbangkan sebelum menerima hadiah, yaitu 1) pertimbangan budaya, 2) waktu penerimaan hadiah, dan 3) jenis hadiah (Zur, 2017; Francis, 2019). Berikut penjelasannya:

\section{Pertimbangan Budaya}

Pemberian hadiah adalah salah satu tradisi sosial tertua yang dikenal manusia. Dalam konteks budaya, untuk membangun hubungan, hadiah diperlukan dalam hubungan tersebut sebagai bentuk penghargaan (Elkatawneh, 2014). Selain aspek klinis-psikologis, pemberian hadiah dalam psikoterapi harus selalu dipertimbangkan dalam konteks budayanya. Lebih sering daripada tidak, makna perilaku memberi hadiah yang berasal dari budaya tertentu hanya dapat dipahami dalam konteks budaya ini (Zur, 2017). Terlepas dari sikap klinis atau etika terapis tentang masalah hadiah, konselor harus menyadari bahwa menolak hadiah kecil dapat berarti penolakan atau tidak hormat kepada individu yang berasal dari budaya yang menekankan keramahan, timbal balik, atau pentingnya hadiah (Zur, 2017).

Mayoritas budaya Barat, ungkapan terima kasih secara verbal tampaknya tepat dan memadai, di banyak budaya non-Barat hadiah yang sebenarnya dan ritual yang menyertainya 
adalah sarana utama untuk mengungkapkan rasa terima kasih, penegasan, dan ikatan emosional (Zur, 2017). Demikian dengan pandangan Corey, Corey, \& Callanan (2011) dalam bekerja dengan populasi konseli yang beragam secara budaya, terapis sering menemukan bahwa mereka perlu terlibat dalam penyeberangan batas untuk meningkatkan hubungan konseling. Konteks budaya memang berperan dalam mengevaluasi kelayakan menerima hadiah dari konseli. Corey, Corey, \& Callanan, (2011) menunjukkan bahwa dalam budaya Asia, pemberian hadiah adalah praktik umum untuk menunjukkan rasa hormat, terima kasih, dan untuk menutup hubungan. Meskipun tindakan tersebut sesuai secara budaya, para profesional yang terlatih di Barat akan percaya bahwa menerima hadiah akan mendistorsi batasan, mengubah hubungan, dan menciptakan konflik kepentingan. Namun, jika seorang konselor menolak hadiah konseli, kemungkinan besar konseli akan merasa terhina penolakan tersebut dapat merusak hubungan konseling.

Berdasarkan pandangan di atas, dapat diketahui bahwa budaya Asia, khususnya di Indonesia ini memberikan hadiah adalah dapat merupakan tanda terima kasih kecil kepada seseorang yang dianggap istimewa atau penting. Karena budaya memaksakan makna, arahan, dan ritual untuk mengungkapkan rasa terima kasih, diharapkan peran budaya harus memiliki beberapa jenis dampak pada pemberian hadiah. Sangat penting bahwa konselor membuat keputusan berdasarkan suara budaya dan nilai-nilai konseli mereka. Tidak melakukannya berpotensi menciptakan perpecahan dalam aliansi terapeutik, karena konseli dapat tersinggung atau merasa ditolak oleh perilaku negatif terapisnya (Taboas, et al., 2014; Witts, Brodhead, Adlington, \& Barron, 2020).

\section{Waktu Pemberian Hadiah}

Waktu pemberian hadiah juga dianggap sebagai faktor penting dalam menentukan makna dan kelayakan hadiah (Corey, Corey, \& Callanan, 2011). Paling umum, hadiah yang diberikan saat akhir konseling dianggap tepat untuk diterima. Berdasarkan penelitian dari Taboas, et al., (2014) menjelaskan bahwa sebagian besar (> 80\%) peserta kami (psikolog/konselor) memiliki sikap positif terhadap menerima hadiah jika mereka ditawarkan pada sesi terakhir, dan mereka mengatakan bahwa hadiah tersebut pantas untuk diterima. Begitupun dengan hasil penelitian Knox, Dubois, Smith, Hess, \& Hill (2009), konseli biasanya memberikan hadiah di akhir sesi konseling. Sebuah hadiah yang diberikan oleh konseli di awal konseling, atau dalam pertengahan konseling, mungkin memerlukan diskusi lebih lanjut dengan konseli, dalam rangka apa konseli memberikan hadiah tersebut kepada konselor. Zur (2017) menjelaskan bahwa hadiah yang diberikan sangat awal dalam proses konseling, adalah hadiah yang eksploitatif atau yang dapat memiliki konotasi seksual harus ditafsirkan dan dihindari (Zur, 2017). Oleh karena itu, konselor perlu memahami bahwa hadiah dapat memainkan arti yang sangat beragam untuk konseli yang berbeda. Masalah kekuasaan, kontrol, rasa syukur, cinta, penghargaan harus dievaluasi secara hati-hati dengan memanfaatkan keterampilan dan pengalaman praktik konseling.

\section{Jenis Hadiah}

Setiap pemberian harus dievaluasi dalam konteks pemberiannya. Selain hadiah selama liburan dan saat pemutusan hubungan kerja, menerima buku, kaset audio, CD, kartu atau puisi yang memiliki arti khusus bagi konseli adalah hal biasa dan dapat diterima. Seorang tukang roti dapat membawa sepotong roti untuk setiap sesi dan seorang petani dapat melakukan hal yang sama dengan beberapa produk misalnya beras. Demikian pula, konseli seniman sering membagikan apresiasi mereka melalui hadiah karya seni mereka, seperti lukisan, patung, selimut tenun, lilin buatan tangan, bangku kayu kecil, labu berukir, kap lampu atau puisi. Witts, Brodhead, Adlington, \& Barron, (2020) juga mengatakan bahwa 
biasanya konselor menerima hadiah dalam bentuk kartu ucapan terima kasih, lukisan tangan, coklat, dan alkohol. Selama hadiah tidak terlalu mahal atau berlebihan mereka cenderung meningkatkan hubungan konseling (Zur, 2017).

Berdasarkan penelitian yang dilakukan oleh Taboas, et al., (2014) yang dilakukan di

Amerika Serikat, sebagian besar dengan peserta Anglo-Amerika melaporkan sikap dan perilaku dari sampel 75 psikoterapis Puerto Rico. Hasil mengungkapkan bahwa sebagian besar $(>80 \%)$ peserta kami memiliki sikap positif terhadap menerima hadiah jika mereka ditawarkan pada sesi terakhir, makanan atau benda yang tidak mahal (kurang dari $\$ 20,00=$ Rp. 288.000), dan ditawarkan oleh seorang anak. Dalam hal perilaku mereka, sekitar $60 \%$ telah menerima hadiah dari konseli mereka. Namun demikian, sekitar 20\% dari sampel kami mendukung pandangan bahwa menerima hadiah adalah pelanggaran etika. Hasilnya ditafsirkan dengan mengambil sudut pandang budaya yang berbeda tentang pemberian hadiah, dan konstruksi cara-cara lokal untuk berperilaku etis. Beberapa rekomendasi dibuat untuk mengklarifikasi bahwa menerima dan menerima hadiah tidak selalu menunjukkan pelanggaran etika (Taboas, et al., 2014).

Kemudian, berdasarkan penelitian Knox, Dubois, Smith, Hess, \& Hill (2009) yang tertuju kepada konseli yang memberikan hadiah, mengatakan bahwa biasanya konseli memberikan hadiah hasil buatannya sendiri, atau membeli sesuatu yang harganya kurang dari $\$ 25=$ Rp. 375.000, dengan jenis hadiah yang menurut mereka disukai oleh konselornya. Selain itu, Penelitian lain menunjukkan fakta bahwa beberapa klien, pada suatu saat selama perawatan psikologis, membawa hadiah kepada terapis mereka. Misalnya, Pope, Tabachnick, Keith-Spiegel, dan Borys (dalam Taboas, et al., 2014) melakukan survei di antara anggota American Psychological Association dan menemukan bahwa sebagian besar terapis menerima berbagai hadiah, kecuali jika nilainya melebihi lebih dari $\$ 50,00=\mathrm{Rp}$. 718.000. Ketika hadiah melebihi jumlah itu, $82 \%$ menganggap bahwa tidak pernah etis atau etis hanya dalam keadaan yang jarang terjadi untuk menerima hadiah tersebut. Sebaliknya, pemberian hadiah yang berlebihan dan hadiah konseli dengan nilai moneter yang tinggi, saham, pinjaman finansial oleh konseli dapat dimengerti, menjadi perhatian banyak terapis, ahli etika, dan dewan lisensi (Zur, 2017). Ada juga contoh di mana bahkan hadiah yang sangat kecil dan murah, seperti kalender porno atau kondom, merupakan hadiah yang tidak pantas (Zur, 2017). Demikian pula, hadiah dengan tema rasis, seksis, pornografi, kekerasan, sugestif seksual, atau tema lain yang menyinggung atau fanatik, terlepas dari nilai uangnya, dianggap tidak pantas dan tidak etis. Berdasarkan penelitian tersebut dapat diketahui bahwa jenis hadiah yang dapat diterima oleh konselor adalah jenis hadiah yang murah, dan sopan.

\section{Kesimpulan}

Berdasarkan kajian di atas dapat disimpulkan bahwa dalam menerima hadiah ada beberapa hal yang perlu dipertimbangkan, diantaranya adalah; 1) pertimbangan budaya, 2) waktu pemberian, 3) dan jenis hadiah. Berdasarkan pertimbangan budaya, khususnya di Asia memandang bahwa menerima hadiah dari konseli adalah hal yang wajar dan patut untuk dilakukan, Berbeda dengan budaya Barat, dalam budaya Barat menerima hadiah akan mendistorsi batasan, mengubah hubungan, dan menciptakan konflik kepentingan. Namun, jika seorang konselor menolak hadiah konseli, kemungkinan besar konseli akan merasa terhina penolakan tersebut dapat merusak hubungan konseling. Kemudian berdasarkan pertimbangan waktu, waktu pemberian hadiah yang layak diterima adalah saat sesi terakhir konseling, lalu jenis hadiah yang layak diterima hadiah tersebut tidak berlebihan dan tidak mengandung unsur SARA. 


\section{Saran}

Saran yang dapat dilakukan oleh peneliti selanjutnya adalah melakukan penelitian survey di Indonesia terkait sikap dan respon konselor/psikolog dalam menerima atau tidaknya hadiah konseli ditinjau dari pertimbangan budaya, waktu, jenis hadiah, alasan konseli memberi hadiah atau tidak memberi hadiah kepada konselor. Supaya wawasan mengenai standar penerimaan hadiah dalam konselor semakin bertambah dan dapat meminimalisir pelanggaran batas atau eksploitasi konseli.

\section{Daftar Pustaka}

ACA. (2014). American Counseling Assosiation (ACA) Code of Ethics. New York : ACA Gouvenir Counseling.

Allan, B. (2017). Ethics Alive- Gifts From Clients The Good the Bad and the Ethically Ugly. The News Social Worker, hal. 1-8.

Beaucoup. (2021). Dipetik Desember 3, 2021, dari beau-coup: https://www.beaucoup.com/articles/accepting-gifts-etiquette.htm

Corey, G., Corey, M. S., \& Callanan, P. (2011). Managing Boundaries and Multiple Relationships. Dalam Issues and Ethics in the Helping Professions. USA: Brooks/Cole, Cengage Learning.

Elkatawneh, H. H. (2014). ETHICAL CODES ACROSS CULTURES: ACCEPTING AND GIVING GIFTS. SSRN Electronic Journal.

Embun. (2012). Penelitian Kepustakaan. Jakarta.

Emerson, J. (t.thn.). Dipetik Desember 3, 2021, dari beaucoup: https://www.beau-coup.com

Francis, P. C. (2019, Agustus). Boundaries and the little things that matter. Counseling Today: Ethics Update, hal. 12-13.

Kimber, S. (2020, Maret 26). Is It Ever Okay to Give or Accept a Gift in Therapy? Dipetik Desember 3, 2021, dari Good Therapy: https://www.goodtherapy.org/forprofessionals/personal-development/therapeutic-alliance/article/is-it-ever-okay-togive-or-accept-gift-in-therapy

Knox, S., Dubois, R., Smith, J., Hess, S. A., \& Hill, C. E. (2009). Clients' Experiences Giving Gifts to Therapists. Psychotherapy Theory Research Practice Training, 46(3), 1-25.

Melfianora. (2017). PENULISAN KARYA TULIS ILMIAH DENGAN STUDI LITERATUR. Pekanbaru: UPT Balai Pelatihan Penyuluh Pertanian.

Pierce, T. J. (2018, September 19). Ethical Dilemma: Is it OK to Accept Gifts from Clients? Dipetik Desember 3, 2021, dari State Bar of Wisconsin: 12/3/21, 8:04 PM Inside Track: Ethical Dilemma: Is it OK to Accept Gifts from Clients?:

Taboas, A. M., Soto, M. M., Dávila, T., Oben, A., Pujals, K., Medina, M., et al. (2014). GIFTS IN PSYCHOTHERAPY: ATTITUDES AND EXPERIENCES OF PUERTO RICAN PSYCHOTHERAPISTS. REVISTA PUERTORRIQUEÑA DE PSICOLOGÍA, 25(2), 328-339.

Witts, B. N., Brodhead, M. T., Adlington, L. C., \& Barron, D. K. (2020). Behavior Analysts Accept Gifts During Practice: So Now What? Behavior Analysis: Research and Practice, 20(3), 196 - 202.

Zed, M. (2014). Metode Penelitian Kepustakaan. Jakarta: Yayasan Obor Indonesia.

Zur, O. (2017). Gifts In Psychotherapy \& Counseling: Ethics, Cultural and Standard of Care Considerations. Dipetik Desember 3, 2021, dari Zur Institute: https://www.zurinstitute.com/gifts-in-therapy/ 